\title{
Sciendo
}

\section{Stability in a Two-Dimensional Dynamical System of Endogenous Growth with Public Capital}

\author{
Aleksandra Borowska \\ Jagiellonian University \\ Łojasiewicza 4 Street \\ 30-348 Kraków, Poland \\ e-mail: aleksandra.borowska@student.uj.edu.pl
}

\begin{abstract}
:
The aim of this study is to present a stability in a two-dimensional dynamical system of endogenous growth with public capital. We assume the simple model of the economic growth, in which both private and public capital can influence on the rate of growth of knowledge. The public capital is rival but non excludable goods, i.e. there is a congestion in use of public capital. The model of growth is formulated as a two-dimensional dynamical system. Using mathematical methods of dynamical systems, we analyze growth paths as well as the stationary states of the system and their stability.

Keywords: economic growth, endogenous growth, public capital.
\end{abstract}

\section{Introduction}

The Solow model [37] describes the dynamics of a simple economy with one input - physical capital. There is a natural way to extend this model including the other forms of capitals, especially human capital [30]. Another choice is the public capital.

There is an increasing role of the public sector in economies and the study of government policy is a central topic of economic dynamical analyses. Public sector economics focuses on budgetary receipts (taxes) and budget expenditure [6]. The purpose of public spending is not only consumption, production of goods, but also investments. Physical public capital is treated as a resource of materials used in the production process. Physical public capital affects the production capacity of the entire economy. At work, we will limit to the analysis of public investment, which results in capital goods, a factor of production such as private capital in kind. In this paper we concentrate on the dynamical analysis of a simple model of economic growth with public capital.

Public capital is set of assets that are own the government and are used for productivity. Examples of public capital are highways, water systems, sewers, airports, roads, transit systems railways, public education, public hospitals, police and fire protection, prisons, and courts, public electric and gas utilities, and telecommunications [3]. 
Public sector capital stock has an impact on private sector production. But on the other hand provision of public sector capital has little effect on private firms' production possibilities [34]. Government can benefit from a more efficient allocation of public resources to attain a higher growth rate [35].

In the earliest models of economic growth public investment was treated as the public expenditure. Barro discussed the model in which the government expenditures raise the marginal productivity of private capital [8]. Then Barro and Sala-i-Martin considered models with rival and excludable publicly provided private goods, non-rival and non-excludable publicly-provided public goods and publicly-provided goods which are the subject of congestion [9].

The alternative approach presented by Greiner who assumed that public inputs are capital goods accumulated in a similar manner as private physical capital [18]. The golden rule of public finances says to finance only long-term investment expenditures with public debt. Greiner [20] proved that greater indebtedness goes hand in hand with smaller long-term growth, obtaining the condition that the increased public spending deficit increases the growth rate. In addition to models of economic growth with a balanced budget, models with a budget deficit will be examined.

We follow Greiner's approach and make two additional assumptions. First, we assume the congestion of the public capital. It means that, for a given level of public capital, the increase of private capital decreases the quantity of public capital to every firm. The production function is of the form proposed by Bajo-Rubio [6]

$$
Y=K^{\alpha} Z_{1}^{\beta_{1}} \ldots Z_{m}^{\beta_{m}}(A L)^{1-\alpha-\beta_{1}-\cdots-\beta_{m}}\left(\frac{G}{K}\right)^{\gamma}\left(\frac{T}{K}\right)^{\theta},
$$

where $\alpha>\gamma+\theta$, and $Y$ denotes output, $K$ is the private physical capital, $G$ is the public physical capital, $Z_{i}$ are other inputs such as, e.g., human capital or public capital, $L$ is labor, $A$ is knowledge and $T$ is transfer.

The second assumption is the dependence of the rate of change of knowledge on the rates of change of capital inputs [36]

$$
\frac{\dot{A}}{A}=a+\mu \frac{\dot{K}}{K}+\nu_{1} \frac{\dot{Z}_{1}}{Z_{1}}+\cdots+\nu_{m} \frac{\dot{Z}_{m}}{Z_{m}}+\nu_{m+1} \frac{\dot{G}}{G} .
$$

To analyze the dynamics of the model we use the methods of dynamical system theory [31]. These method are especially suitable to study the dynamics of nonlinear economic systems [27]. They allow to determine qualitatively the regions of initial conditions for which trajectories reach the same asymptotic state (steady-state point). Qualitative behavior of dynamical systems depend on the values of model parameters. The change of behavior due to the change of the value of parameter is a scope of the bifurcation theory $[13,22]$.

Apart from analytical methods of dynamical systems, we use numerical methods of integration of differential equations. This allows us to present phase portraits of system under study as well as investigate the bifurcations in details.

\section{The Model}

We consider the economy where output $Y$ is produced by using physical private capital $K$, physical public capital $G$, labor $L$, and knowledge $A$ as inputs 


$$
Y(t)=F(K(t), G(t), A(t), L(t)) .
$$

We assume the neoclassical production function, proposed by Bajo-Rubio [6], in the simplified form

$$
Y(t)=K^{\alpha}(t)[A(t) L(t)]^{1-\alpha}\left[\frac{G(t)}{K(t)}\right]^{\beta},
$$

where $0<\beta<\alpha<1$.

We make the standard assumption that the labor grows with the constant rate $n$

$$
\frac{\dot{L}(t)}{L(t)}=n
$$

In the neoclassical model of economic growth it is assumed that knowledge $A$ grows with the constant rate $a$. We relax this assumption and assume that apart from the exogenous growth of knowledge both private and public capital can influence on the rate of growth of knowledge. We assume that these processes are additive and proportional to rates of growth of these capitals

$$
\frac{\dot{A}(t)}{A(t)}=a+\mu \frac{\dot{K}(t)}{K(t)}+\nu \frac{\dot{G}(t)}{G(t)}
$$

or

$$
A(t)=A_{0} e^{a t} K^{\mu}(t) G^{v}(t),
$$

where $\mu$ is rate of growth of private capital and $v$ is rate of growth of public capital. The change of the private capital is equal to the net investment

$$
K^{\cdot}(t)=s(1-\tau) Y(t)-\delta K(t)
$$

while the change of the public capital is given by

$$
G^{\cdot}(t)=\tau Y(t)-\delta G(t)
$$

where we assume that both private and public capital depreciate with the rate $\delta$, and $s$ and $\tau$ are the rates of saving and tax, respectively. Let us introduce the new variables

$$
k=\frac{K}{A L}, \quad g=\frac{G}{A L} .
$$

Then the system of equations (5), (6), (8), (9) can be reduced to the two - dimensional dynamical system

$$
\begin{aligned}
& \dot{k}(t)=s(1-\tau)(1-\mu) k^{\alpha-\beta}(t) g^{\beta}(t)-\tau v k^{\alpha-\beta+1}(t) g^{\beta-1}(t)-d k(t) \\
& g^{\cdot}(t)=\tau(1-v) k^{\alpha-\beta}(t) g^{\beta}(t)-s(1-\tau) \mu k^{\alpha-\beta-1}(t) g^{\beta+1}(t)-d g(t)
\end{aligned}
$$

where

$$
d=(1-\mu-v) \delta+n+a \text {. }
$$




\section{Local Stability Analysis}

For the two-dimensional dynamical system in the form

$$
\begin{aligned}
& \frac{d x}{d t} \equiv \dot{x}=P(x, y) \\
& \frac{d y}{d t} \equiv \dot{y}=Q(x, y)
\end{aligned}
$$

The critical point $\left(x^{*}, y^{*}\right)$ is determined as a solution of the system

$$
\begin{aligned}
& P(x, y)=0, \\
& Q(x, y)=0 .
\end{aligned}
$$

To determine the character of the critical point $\left(x^{*}, y^{*}\right)$, first, we find the linearization matrix

$$
A=\left[\begin{array}{ll}
\left.\frac{d P(x, y)}{d x}\right|_{x=x^{*}, y=y^{*}} & \left.\frac{d P(x, y)}{d y}\right|_{x=x^{*}, y=y^{*}} \\
\left.\frac{d Q(x, y)}{d x}\right|_{x=x^{*}, y=y^{*}} & \left.\frac{d Q(x, y)}{d y}\right|_{x=x^{*}, y=y^{*}}
\end{array}\right]
$$

and then we solve the characteristic equation

$$
\lambda^{2}-(\operatorname{tr} A) \lambda+\operatorname{det} A=0
$$

where $\lambda$ is an eigenvalue of the linearization matrix $A$, and $\operatorname{tr} A$ and $\operatorname{det} A$ are the trace and the determinant of matrix $A$, respectively.

The eigenvalues can be real or complex (positive or negative discriminant $(\operatorname{tr} A)^{2}-4 \operatorname{det} A$ ). If the eigenvalues are real, different signs, the critical point is a saddle. If the eigenvalues are real of the same sign the critical point is a node (stable for negative eigenvalues or unstable for positive eigenvalues). If the eigenvalues are complex with a zero real part, the critical point is a center. If the eigenvalues are complex with a non-zero real part, the critical point is a focus (stable for negative real part of the eigenvalue or unstable for positive real part of the eigenvalue).

There are two critical points of the system (11) in the finite domain of the phase space. The first, trivial point is

$$
k_{1}^{*}=0, \quad g_{1}^{*}=0 .
$$

The second critical point lies inside the domain $k>0$ and $g>0$ and it is the only critical point in this domain and it is an attractor for all trajectories with initial conditions in this domain

$$
\begin{aligned}
& k^{*}=\left(\frac{d}{\tau(1-\mu-\nu)}\right)^{\frac{1}{\alpha-1}}\left(\frac{s(1-\tau)}{\tau}\right)^{\frac{\beta-1}{\alpha-1}}, \\
& g^{*}=\left(\frac{d}{\tau(1-\mu-\nu)}\right)^{\frac{1}{\alpha-1}}\left(\frac{s(1-\tau)}{\tau}\right)^{\frac{\beta-\alpha}{\alpha-1}}
\end{aligned}
$$

To determine the character of critical point 18 , we calculate the linearization matrix at this point 


$$
A=\left[\begin{array}{ll}
a_{11} & a_{12} \\
a_{21} & a_{22}
\end{array}\right]
$$

where

$$
\begin{aligned}
& a_{11}=d\left(\frac{(1-\mu)(\alpha-\beta)-\nu(\alpha-\beta+1)}{1-\mu-\nu}-1\right), \\
& a_{12}=\frac{d s(1-\tau)}{(1-\nu-\mu) \tau}[(1-\mu) \beta-(\beta-1) \nu], \\
& a_{21}=\frac{\tau d}{s(1-\mu-\nu)(1-\tau)}[(1-\nu)(\alpha-\beta)-\mu(\alpha-\beta-1)], \\
& a_{22}=d\left(\frac{\beta(1-\nu)-\mu(\beta+1)}{1-\mu-\nu}-1\right) .
\end{aligned}
$$

Solving the characteristic equation we find that there are two distinct real negative eigenvalues. This point is a stable node.

$$
\begin{aligned}
& \lambda_{1}=-\frac{d}{1-\mu-\nu} \\
& \lambda_{2}=d(\alpha-1) .
\end{aligned}
$$

\section{Saddle-node Bifurcation}

In this section we study local bifurcation in the system (23). Assume that we have a two-dimensional dynamical system

$$
\begin{gathered}
\dot{k}(t)=s(1-\tau)(1-\mu) k^{\alpha-\beta}(t) g^{\beta}(t)-\tau v k^{\alpha-\beta+1}(t) g^{\beta-1}(t)-d k(t), \\
g^{\cdot}(t)=\tau(1-v) k^{\alpha-\beta}(t) g^{\beta}(t)-s(1-\tau) \mu k^{\alpha-\beta-1}(t) g^{\beta+1}(t)-d g(t) .
\end{gathered}
$$

We solve the characteristic equation

In our case:

$$
\lambda^{2}-(\operatorname{tr} A) \lambda+\operatorname{det} A=0 .
$$

$$
\begin{gathered}
\operatorname{det} A=\frac{d^{2}(1-\alpha)}{1-\mu-\nu}, \\
\operatorname{tr} A=\frac{d}{1-\nu-\mu}((\alpha-2)(1-\nu-\mu)-(\mu+\nu)) .
\end{gathered}
$$

Proposition 1 The saddle-node bifurcation arises if and only if $\operatorname{det} A=0$.

In this case $\frac{d^{2}(1-\alpha)}{1-\mu-\nu}=0$ only if $v=1-\mu+\frac{n^{+}}{\delta} \underline{\underline{a}}$ and $1 \neq \mu+v$.

Proposition 2 In the case of a two-dimentional system, a Hopf bifurcation generally arises if and only if $\operatorname{det} A=\operatorname{tr} A$. The saddle-node bifurcation arises if and only if $\operatorname{det} A=\operatorname{tr} A$. 
Hopf bifurcation does not appear in this model.

\section{Conclusions}

In this paper we considered the model of economic growth with public capital to present an impact of the public capital and knowledge on the economic growth from a theoretical perspective. we consider the economy where output is produced by using private capital, public capital, labor and knowledge as inputs. In the model we assume that both public and private capital can influence on the rate of growth of knowledge. In the work we consider that for a given level of public capital, the increase of private capital decreases the quantity of public capital to every firm.

1) The dynamics of the model can be represented as a two-dimensional dynamical system in variables: a ratio of rate of public and private capital torate of knowledge, tax and level of labor. We obtained the critical point of the model is a stable node.

2) In the model we find the saddle-node bifurcation. Due to this bifurcation, the saddle critical point is created toward which the system evolves along the stable optimal path.

\section{The Further Research}

In this project we are going to extend the study the model, in particular

- we study the dependence of model solution on the model parameters; we use the methods of bifurcation analysis to this aim;

- we consider the Ramsey problem in this model; as a result we obtain the three-dimensional dynamical system which will be a subject to a thorough scrutiny;

- the numerical analysis of the models will be made.

\section{References}

1. Acemoglu, D. Technology, unemployment and efficiency. European Economic Review 41, 1997, pp. 525-533.

2. Arrow, K. J., and M. Kurz. Public investment, the rate of return, and optimal fiscal policy, New York: The Johns Hopkins University Press, 1970.

3. Aschauer, D. A. Does public capital crowd out private capital? Journal of Monetary Economics 24, 1989, pp. 171-188.

4. Aschauer, D. A. Is public expenditure productive? Journal of Monetary Economics 23, 1988, pp. 177-200.

5. Aschauer, D. A. Public investment and productivity growth in the Group of Seven, Economic Perspectives 13, 1999, pp. 17-25.

6. Bajo-Rubio, O. A further generalization of the Solow model: the role of the public sector, Economics Letters 68 (5), 2000, pp. 79-84.

7. Barnett, W. A., and G. Chen. Bifurcation of macroeconomic models and robustness of dynamical inferences, Studies in Applied Economics SAE./No.32/April 2015.

8. Barro, R. Government spending in a simple model of endogenous growth, Journal of Political Economy 98, 1990, pp. 103-125.

9. Barro R., and X. Sala-i-Martin. Public finance in models of economic growth, Review of Economic Studies 59, 1992, pp. 645-661.

10. Beavis, B., and I. M. Dobbs. Optimization andstability theory for economic analysis, Cambridge: Cambridge University Press, 1990. 
11. Bosi, S., and D. Desmarchelier. Local bifurcations of three and fourdimensional systems: A tractable characterization with economic applications. Mathematical Social Sciences 97, 2019, pp. 38-50.

12. Brown, C. V., and P. M. Jackson. Public Sector Economics, $4^{\text {th }}$ ed., Oxford: Blackwell, 1990.

13. Chow, S.-N., and J. K. Hale. Methods of Bifurcation Theory, Vol. 251 of Grundlehren der mathematischen Wissenschaften: A Series of Comprehensive Studies in Mathematics, New York: Springer, 1982.

14. Futagami, K., T. Iwaisako, and R. Ohdoi. Debt policy rule, productive government spending, and multiple growth paths, Macroeconomic Dynamics 12, 2008, pp. 445-462.

15. Futagami, K., Y. Morita, and A. Shibata. Dynamic analysis of an endogenous growth model with public capital, Scandinavian Journal of Economics 95, 1993, pp. 607-625.

16. Glomm, G., and B. Ravikumar. Public versus private investmentin human capital: Endogenous growth and income distribution, Journal of Political Economy 100, 1992, pp. 818-834.

17. Greiner, A. An endogenous growth model with public capital and sustainable government debt, Japanese Economic Review 58, 2007, pp. 345-361.

18. Greiner, A. Fiscal Policy and Economic Growth, Avebury: Aldershot, 1996.

19. Greiner, A. Human capital formation, public debt and economic growth, Journal of Macroeconomics 30, 2008, pp. 415-427.

20. Greiner, A. Public debt, productive public spending and endogenous growth. Japanese Economic Review 66, 2015.

21. Greiner, A., and B. Fincke. Public Debt, Sustainability and Economic Growth, New York: Springer, 2015.

22. Hale, J. K., and H. Kocak. Dynamics and Bifurcations, Vol. 3 of Texts in Applied Mathematics, New York: Springer, 1991.

23. Heer, B. Public Economic. The Macroeconomic Perspective, Cham: Springer, 2019.

24. Holtz-Eakin, D. Public-Sector Capital and the Productivity Puzzle, NBER Working Paper No. 4122, July 1992.

25. Kalaitzidakis, P., and S. Kalyvitis. Financing 'New' Public Investment and/or Maintenance in Public Capital for Growth? The Canadian Experience, Economic Inquiry 43, 2005, pp. 586-600.

26. Khibnik, A., Y. Kuznetsov, V. Levitin, and E. Nikolaev. Continuation techniques and interactive software for bifurcation analysis of ODE's and iterated maps, Physica D 62, 1993, pp. 360-371.

27. Lorenz, H.-W. Nonlinear Dynamical Economics and Chaotic Motion, 2nd Edition, Berlin: Springer-Verlag, 1993.

28. Lucas, R. E. On the mechanics of economic development. Journal of Monetary Economics 22, 1988, pp. 3-42.

29. Lynde, C., and J. Richmond. The role of public capital in production, The Review of Economics and Statistics 74 (1), 1991, pp. 37-44.

30. Mankiw, N. G., D. Romer, and D. N. Weil. A contribution to the empirics of economic growth, Quarterly Journal of Economics 107 (2), 1992, pp. 407-437.

31. Perko, L. Differential Equations and Dynamical Systems, 3rd Edition, Vol. 7 of Texts in Applied Mathematics, New York: Springer, 2001.

32. Reinhart, C. M., and K. S. Rogoff. Growth in a time of debt, NBER Working Paper No. 15639, 2010.

33. Romer, P. M. Endogenous technological change, Journal of Political Economy 98, 1990, pp. 71102.

34. Romer, P. M. Increasing returns and long-run growth, Journal of Political Economy 94, 1986, pp. 1002-1037. 
35. Saint-Paul, G. Technological choice, financial markets and economic development. Eur. Econ. Rev. 36 (4), 1992, pp. 763-781.

36. Sims, C. A. A simple model for study of the determination of the price level and the interaction of monetary and fiscal policy. Economic Theory 4, 1994, pp. 381-399.

37. Solow, R. W. A contribution to the theory of economic growth, Quarterly Journal of Economics 70 (1), 1956, pp. 65-94.

38. Szydłowski, M., and A. Krawiec. On capital dependent dynamics of knowledge, Acta Physica Polonica B37, 2006, pp. 3161-3170.

39. $\mathrm{Wu}, \mathrm{Y}$., and J. Zhang. Endogenous growth and the welfare costs of inflation: A reconsideration, Journal of Economic Dynamics and Control, 22, 1998, pp. 465-482.

40. Yakita, A. Sustainability of public debt, public capital formation, and endogenous growth in an overlapping generations framework, Journal of Public Economics 92, 2008, pp. 897-914. 